relationships by a totally different set of 'facts' stretching backwards into the past, as if we saw only the green in a landscape and they saw only the red."

The inevitable prejudice of human judgment finds a corrective in a natural love of justice. But this corrective requires (1) organization and (2) external application. The requisite institutional remedy lies in law, such as we already have it within our nation States. The inevitability of national prejudice requires that such law shall be organized and administered upon a supernational plane.

\section{PHYSICS, MATERIALISM, AND FREE WILL}

\section{By Prof. L. SUSAN STEBBING University of London}

$\mathrm{S}^{\mathrm{s}}$ R JAMES JEANS'S recent book, "Physics and Philosophy", has once more raised the question of the bearing of the 'new physics' upon the philosophical doctrines of metaphysical materialism and human free will. It is not a little odd that at a time when some philosophers are beginning to wonder whether it makes sense to say that materialism is true (or that it is false), and whether, therefore, it makes sense to say that idealism is true (or that it is false), some eminent physicists and mathematicians are asserting that the new physics provides arguments that are very strong, even if not conclusive, in favour of establishing the truth of metaphysical idealism. Thus, for example, Sir James Jeans concludes : "Modern physics is not altogether antag. onistic to an objective idealism like that of Hegel"*. $\mathrm{He}$ further contends that the new physics has an important bearing upon the problem of free will.

These two contentions formed the main topic of discussion at the symposium held at a joint meeting of the London and Home Counties Branch of the Institute of Physics, the Aristotelian Society, and the Mind Association, on May 19. I gave the opening paper, which was replied to by Sir James Jeans; Mr. R. B. Braithwaite and Prof. E. T. Whittaker opened the discussion which followed. This article is not a report of the discussion, but an attempt to bring out the main points that were raised.

There is a preliminary question which usually receives far too little discussion, namely, what exactly is the relation of physics and philosophy. Not all philosophers would give the same answer to this question, nor would all physicists. What Sir James Jeans's answer would be is well known; he holds that metaphysics is literally 'beyond physics', so that the decision whether materialism is true or is false is one to be made by physicists. Since it is assumed that the denial of materialism entails the assertion of idealism, it can scarcely be maintained that the physicist qua physicist has a right to the last word. Before that last word is said, he must have become a philosopher and have acquired some skill in thinking philosophically. It is also desirable that he should have learnt to avoid the mistakes of earlier philosophers, which have been quite decisively refuted. Certainly any man of science may well be led to reflect upon certain great problems which have traditionally occupied the attention of philosophers

" "Physics and Philosophy", p. 204. -man's place in the universe, the ultimate nature of things, of matter and of mind, and of their interconnexion. Such problems have also exercised the minds of some great poets. In what sense these great questions are 'problems' can only be asked at a comparatively late stage of philosophical development. Physicists are sometimes tempted to take short cuts and to say more than they know.

Prof. E. T. Whittaker has made a very pertinent comment in this connexion. He ascribes the extraordinary popularity of the writings of Sir Arthur Eddington and Sir James Jeans not to their eminence as men of science, nor to their powers of exposition, but to the fact that, as he said, "they have ar quality which is found, perhaps, most markedly in great poets, of having flashes of insight which reveal to them things which are beyond the range of exact knowledge. Whereas, knowing them to be eminent scientists, we imagine that what we are going to get from them is exact knowledge, we are delighted to find that they have a poetic insight."* This comment seems to me to be just. To keep to the case of Sir James Jeans, his philosophical reaction to 'the implications of the new physics' appears to be largely determined by his feeling that "the new physics shows us a universe which looks as though it might conceivably form a suitable dwelling-place for free men, and not a mere shelter for brutes-a home in which it may at least be possible for us to mould events to our desires and live lives of endeavour and achievement". These are not the remarks of a physicist writing physics; they are the reflexions of a physicist who is attempting to formulate a philosophy of life. It is from this point of view that they must be judged; criteria derived from physics will not suffice.

The old physics (that is, classical physics, which reached its consummation in the nineteenth century) is thought to be inimical to our desires because it is taken to involve the doctrine that the ultimate reality is matter and that mind is a mere epiphenomenon of matter. This doctrine has been associated with a strict determinism, that is, with the view that all events, including human volitions, are causally connected so that our thoughts and feelings could, in principle, be predicted; everything that happens is, in fact, nothing but a mere re-arrangement of the atoms that are the ultimate constituents of the universe, and alone are permanent. The 'prisonhouse' feeling, or what T. H. Huxley called "the nightmare", has been induced by the reluctant acceptance of materialism in this form together with the strict determinism associated with it.

Anyone who has accepted this metaphysical theory as an inescapable outcome of classical physics will be likely to welcome the new physics as being very relevant to the solution of his problem. It is, however, important to be clear with regard to what exactly the problem is. It appears to be the problem of escaping from the 'prison-house' into a world in which we may hope "to mould events to our desires". If the obstacle to this escape has been the acceptance of the view that the universe 'really' consists of indestructible atoms and that the perceptible variety of things in the universe and the perceptible difference between men, brutes, and, for example, rocks, are

* I quote from a verbatim report of the discussion, kindly provided for me by the chairman of the symposium. Prof. Whittaker went on to say that I had not altogether allowed for this fact. I think he is right in stressing this difference of temperament, and in insisting that I am not in the least 'poetic'. It would be interesting to learn whether Sir Arthur and Sir James are content to regard their excursions into
philosophy as mainly poetic in quality. 
wholly due to differences in the arrangements of these atoms, all of which move in accordance with strict causal laws, then the possibility of escape begins to appear promising. The new physics has shown conclusively that this atomic conception is mistaken and that, to quote Prof. Whittaker, "determinism does not reign definitely in the physical world".

It is at this point that the philosophy of Sir James Jeans becomes significant. His contention is that there is a new dualism of waves and particles replacing the old dualism of mind and matter. Readers of NATURE will not require any exposition of this view. Philosophers will wish to ask why exactly Sir James Jeans holds that the 'wave-picture' is more fundamental than the 'particle-picture', and what is the logical basis of his contention that the waves are mental and the particles material, or, as he also puts it, that the wave-picture gives us knowledge and the particle-picture gives us objects. Further, on what grounds does he contend that the waves control the particles; hence that mind controls objects ?

In elaiming that the wave-picture is mental, Sir James Jeans seems to have been influenced by three considerations : (1) that the geometrical representation of the waves is more complicated than the geometrical representation required by classical physics ; (2) that wave mechanics is a mental construct whereas particle mechanics either is not a mental construct, or at least is not a mental construct in the same sense; (3) that since the waves are waves of knowledge, the determinism involved in the wavepicture originates in part at least in our own minds. It is not clear whether Sir James Jeans considers that (2) follows from (1), but it seems that he must have done so. There is not, in my opinion, any good reason for this contention. Wave mechanics is just as much or just as little a construct as particle mechanics. Hence, if idealistic conclusions are to be drawn from the new physics, they could just as suitably be drawn from classical physics; in fact, they cannot suitably be drawn from either. (3) would appear to be jointly entailed by (1) and (2). Nothing in the discussion or in Sir James Jeans's book shows clearly what exactly are his views with regard to the nature of mathematics. At times he seems to suppose that a mathematical statement is a statement about something mental; at other times he suggests that "God made the mathematics and man made the rest" (in physics). However we interpret this cryptic utterance, it does not seem likely to support the conclusion that objective idealism is in the main correct.

Plain men, especially during the last two centuries, have been apt to take their philosophy from science, meekly accepting whatever scientific men tell them to believe, and thus they are led to deny the plain facts of their own experience if eminent men of science exhort them to do so. It is odd how easily plain men and scientific men alike forget the nature of the abstractions within which experimental science is carried on. Although plain men find difficulty in recognizing themselves as 'cogs in a machine', they see that, if the universe is a great machine, they must indeed be nothing better than cogs. They forget that physics is concerned with certain features in the universe, to the entire exclusion of other features. Accordingly, the rejection of the machineimage is hailed with delight as freeing us from the 'prison-house'. All this is very understandable, but completely without logical foundation. If this be correct, the bearing of the new physics upon the problems raised by Sir James Jeans is psychological; it enables him, and others, to feel differently about the position of men in the physical universe. It has, however, no bearing at all upon the question whether metaphysical materialism is false, or whether the assertion that metaphysical materialism is true or false is itself a statement without assignable meaning.

It may further be urged that, even if the new physics destroyed the basis of the nineteenth century denial of human freedom, there would still remain a greater obstacle to overcome, namely, the part played by man's glandular structure upon his activities. This contention, it may be noted, was not favourably received by the physicists.

\section{BREAST AND BOTTLE FEEDING}

A BOUT half the babies born in Great Britain nowa. days are put on the bottle between the third and sixth months after birth ; the proportion is increasing, but in spite of this the health of babies is undoubtedly improving. It is inevitable that a discussion such as that of the Nutrition Society on May 22 about nutrition in infancy should continually suggest the question : Is there any serious objection to stopping breast feeding after the first few months?

It is easy to suppose that, through thousands of years of selection, a mechanism has evolved that will provide the baby with ideal food, if the mother is supplied with the necessary materials in her own food. But evolution cannot anticipate changes in environment. Piglets kept in a bare sty become seriously anæmic in a few weeks; the sow's milk does not supply them with the iron they need, how. ever much she may be taking'. In their natural state the piglets would pick up enough by rooting in the earth ; in the sty they must be given iron in some form. Man takes his women and babies into equally unnatural environments which may impose demands that the mother's milk will not cover. The amount of vitamin $D$ that is ample for a naked baby in a sunny climate may be wholly insufficient for a baby screened from ultra-violet light by clouds, smoke, house and clothes. It is possible that artificial milk might be prepared that would meet a modern baby's needs better than any human milk.

The disastrous results of artificial feeding in the past were due to dirt and infection with pathogenic bacteria. Milk supplies were filthy; bottles were not clean, often because they were so shaped that it was not possible to clean them; the baby drank an infusion of bacteria, dead or alive. Even if the bacteria were not pathogenic they did not agree with baby. In the last twenty years milk has become cleaner; much that is now supplied to cities is pasteurized; the pattern of bottles has improved and mothers have learned how to use them; house-flies have almost vanished with the horse from cities. These changes have taken away most of the terrors of bottle feeding and of the first few months after weaning. Nine years ago, Grulee ${ }^{2}$ published figures to show that the deathrate of bottle-fed infants was nearly ten times as high as that of the breast-fed. But that was more than nine years ago and, as was pointed out at the Nutrition Society's meeting, Grulee made his investigations among the slum population of Chicago. The "slum population of Chicago" may not be so bad as it sounds, 